\title{
Singularities in Geometry and Topology
}

Proceedings of the Trieste Singularity Summer School and Workshop 
This page intentionally left blank 


\section{Singularities in Geometry and Topology}

Proceedings of the Trieste Singularity Summer School and Workshop

ICTP, Trieste, Italy 15 August - 3 September 2005

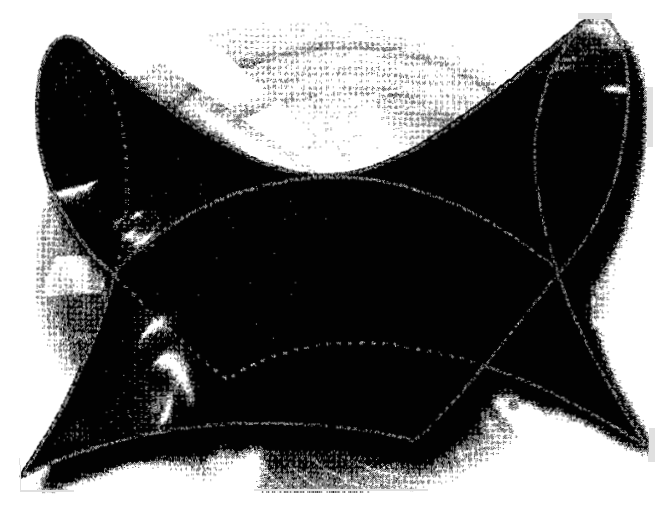

Editors

Jean-Paul Brasselet

Institut de Mathématiques de Luminy-CNRS, France

James Damon

University of North Carolina, USA

Lê Dũng Tráng

ICTP, Trieste, Italy

Mutsuo Oka

Tokyo University of Science, Japan

\section{World Scientific}




\section{Published by}

World Scientific Publishing Co. Pte. Ltd.

5 Toh Tuck Link, Singapore 596224

USA office: 27 Warren Street, Suite 401-402, Hackensack, NJ 07601

UK office: 57 Shelton Street, Covent Garden, London WC2H 9HE

\section{British Library Cataloguing-in-Publication Data}

A catalogue record for this book is available from the British Library.

\section{SINGULARITIES IN GEOMETRY AND TOPOLOGY \\ Proceedings of the Trieste Singularity Summer School}

Copyright @ 2007 by World Scientific Publishing Co. Pte. Ltd.

All rights reserved. This book, or parts thereof, may not be reproduced in any form or by any means, electronic or mechanical, including photocopying, recording or any information storage and retrieval system now known or to be invented, without written permission from the Publisher.

For photocopying of material in this volume, please pay a copying fee through the Copyright Clearance Center, Inc., 222 Rosewood Drive, Danvers, MA 01923, USA. In this case permission to photocopy is not required from the publisher.

ISBN-13 978-981-270-022-3

ISBN-10 981-270-022-6 


\section{INTRODUCTION}

In August-September 1991, the first meeting on singularities at the International Centre of Theoretical Physics (ICTP) was held. It was organized by V.I. Arnold, Lê Dũng Tráng, K. Saito and B. Teissier. That meeting can be viewed historically as a continuation of earlier major conferences in singularities held in Liverpool (1970-71), Cargese (Corsica) in 1972, Arcata (California) in 1981 and Lille (June 1991).

Since then, there have been a number of international meetings on singularities, in Luminy (France), Cracow (Poland), Sapporo (Japan) and Liverpool (UK) among others. In 2000 an entire semester at the Isaac Newton Institute was devoted to singularities, making it one of the important events of the past decade. With the exception of the 1991 Trieste meeting (published by World Scientific Publishers in 1993), the proceedings for these conferences concentrated on the most current research advances. What has been lacking is a collection of surveys and introductions on diverse areas of singularities which a non-expert reader could use to learn the basic ideas in these areas.

With this in mind, the editors decided to gather in a new volume the contents of the lectures given at the ICTP School on Singularities and Applications in August-September 2005. For this volume, we have included surveys and basic introductions by leading experts to various aspects of singularity theory, exactly to provide students and non-experts with the desired access. At the same time, where appropriate certain advanced and noteworthy articles have been included. To help guide the reader, we have organized the book so that papers which survey results and provide an introduction to a subfield are gathered in the first part of the book. The second part contains original research papers principally describing results from invited lectures. All the papers that appear here have been refereed.

This volume complements the volume of proceedings of the Luminy School on Singularity Theory and Applications held in January-February 2005, which is also being published by World Scientific Publishers. The meetings had different emphasis, with that in Trieste placing greater emphasis on the underlying theory which is a basis for more advanced work.

We hope that this presentation of recent trends in singularity theory will become a basic tool for scientists who desire to understand the role of singularities in mathematics.

We wish to acknowledge the generous support of ICTP, with its emphasis on financial assistance for participating students and researchers from 
developing countries. Our thanks are also extended to the staff of ICTP, especially Mabilo Koutou for their considerable help in the organization of the conference. Finally, we thank all of the speakers whose contributions appear in the proceedings and all of the participants who contributed to the success of the event.

Jean-Paul Brasselet James Damon Lê Dũng Tráng Mutsuo Oka 




Advanced School and Workshop on Singularities in Geometry and Topology 14 August-3 September 2005 ICTP, Trieste, Italy 
This page intentionally left blank 
CONTENTS

\section{Introduction}

Part I Elementary School on Singularity Theory

Introduction to Basic Toric Geometry

G. Barthel, L. Kaup and K.-H. Fieseler

Poincaré-Hopf Theorems on Singular Varieties J.-P. Brasselet

Notes on Real and Complex Analytic and Semianalytic

Singularities

D. B. Massey and D. T. Lê

On Milnor's Fibration Theorem for Real and Complex

Singularities

J. Seade

Introduction to Complex Analytic Geometry

T. Suwa

\section{Part II Advanced School on Singularity Theory}

Metric Theory of Singularities. Lipschitz Geometry of Singular Spaces

L. Birbrair

Lectures on Monodromy

W. Ebeling and S. M. Gusein-Zade

Computational Aspects of Singularities

A. Frühbis-Krüger

Lagrangian and Legendrian Varieties and Stability of Their Projections

V. V. Goryunov and V. M. Zakalyukin

A Resolution of Singularities of a Toric Variety and a Non-degenerate Hypersurface

S. Ishii

Problems in Topology of the Complements to Plane Singular

Curves

A. Libgober 
Topology of Degeneration of Riemann Surfaces

Y. Matsumoto

Graded Roots and Singularities

A. Némethi

Chern Classes and Thom Polynomials

T. Ohmoto

McKay Correspondence for Quotient Surface Singularities

o. Riemenschneider

Lectures on the Topology of Polynomial Functions and

Singularities at Infinity

D. Siersma and $M$. Tibăr

Hodge Theory: The Search for Purity

C. A. M. Peters and J. H. M. Steenbrink

556

\section{Part III Workshop on Singularities in Geometry} and Topology

On Sufficiency of Jets

H. Brodersen

Singularity Theory Approach to Time Averaged Optimization

A. Davydov and H. Mena-Matos

Indices of Collections of 1-Forms

W. Ebeling and S. M. Gusein-Zade

A Lefschetz Theorem on the Picard Group of Complex Projective Varieties

H. A. Hamm and D. T. Lê

640

Braid Monodromy and $\pi_{1}$ of Discriminant Complements

M. Lönne

661

Tangential Alexander Polynomials and Non-reduced Degeneration

M. Oka

On Rigidity of Germs of Holomorphic Dicritic Foliations and Formal Normal Forms

E. Rosales-González

Polar Multiplicities and Euler Obstruction of the Stable Types in Weighted Homogeneous Map Germs from $\mathbb{C}^{n}$ to $\mathbb{C}^{3}, n \geq 3$

E. C. Rizziolli and M. J. Saia 
Logarithmic Vector Fields and Multiplication Table

S. Tanabé

Some Surface Singularities Obtained via Lie Algebras K. Nakamoto and M. Tosun

Maxwell Strata and Caustics

$M$. van Manen

Complex Curve Singularities: A Biased Introduction

B. Teissier

Programme of the Conference

List of Participants 